\title{
Visual Context and Relevance in Life Cycle Diagrams
}

\author{
Matthew Wood ${ }^{1,2^{*}}$, Susan Stocklmayer ${ }^{1}$
}

\author{
${ }^{1}$ Australian National University, AUSTRALIA \\ 2 University of Tsukuba, JAPAN \\ *Corresponding Author: mattwood@biol.tsukuba.ac.jp
}

Citation: Wood, M., \& Stocklmayer, S. (2021). Visual context and relevance in life cycle diagrams. Interdisciplinary Journal of Environmental and Science Education, 17(1), e2224. https://doi.org/ 10.29333/ijese/ 9154

\begin{abstract}
ARTICLE INFO
ABSTRACT

Received:

11 June 2020

Accepted:

13 August 2020

Graphics, graphs, diagrams, and visual representations of information play an integral role in science education and communication settings. The production of such graphics involves hundreds of design decisions, from content and layout to colour and illustration style, and any of these decisions has the potential to influence viewer's experience and interpretation. While many studies have examined the influence of design on information transfer, comprehension, recall and so on, less attention has been given to affective impacts. In this study, we examined the impact of visual context in a biology life cycle diagram on viewers' perception of relevance, sense of concern, and others. Results indicated that the presence of a contextual background in the diagram was associated with higher perception of relevance (related to personal experience). Context may also correlate with greater concern, though further research is needed to confirm this.
\end{abstract}

Keywords: affect, relevance, visual context, diagram design

\section{INTRODUCTION}

Graphical representations of information, such as instructional diagrams, flowcharts, infographics, and so on are commonplace in our daily environment. This is an increasing trend as digital tools make graphics easier and cheaper to produce, and as audiences' expectations for visualised information grow. The communication of science is especially dependant on graphical representations. Graphics and diagrams are essential tools for scientists to discuss, communicate and even conceptualise their research, as is discussed in more detail by Cook (2006). Graphics are also widely used for the public communication of science, and Trumbo (2000) pointed out that the recent proliferation of science images in general media has created a need for more research to determine what in fact these images communicate.

Research on graphics tends to focus on the interpretation and understanding of information from graphs and diagrams and the like. Much of this work targets what we will refer to as cognitive outcomes-information transfer, data reading, the development of mental models, recall, and so on. This is perfectly reasonable of course, since science diagrams and graphics are commonly used in educational, research, or other settings where such outcomes are a primary concern. Research of this nature on seductive details (e.g. Wiley, 2019), naïve realism (e.g. Hegarty, Smallman, \& Stull, 2012; Smallman \& St John, 2005), and multimedia design (e.g. Mayer \& Moreno, 2002), along with broader frameworks such as Cognitive Load Theory (Cook, 2006) support a reductionist trend in the design of instructional graphics to reduce extraneous details and strive for focused simplicity.

However other affective, emotional, or attitudinal influences of graphics which may be important for communicators, remain largely unexplored. For example, in addition to educating their audience, environmental communicators may also strive for an emotional impact aimed at changing behaviour. Similarly, a graphic's influence on interest and motivation (in addition to understanding) may be of use to science communicators and science educators.

There are of course exceptions to this trend toward a purely cognitive focus, and notable examples include acknowledgements of potential emotional and 
motivational impacts of seductive details (e.g. Park, Flowerday, \& Brünken, 2015; Park, Moreno, Seufert, \& Brünken, 2011), and the influence of emotional design (attention to aesthetics, colour, anthropomorphism, or decorative photographs) on viewer mood and subsequent learning (e.g. Heidig, Müller, \& Reichelt, 2015; Plass, Heidig, Hayward, Homer, \& Um, 2014; Schneider, Nebel, \& Rey, 2016). This study aims to extend on our understanding of affective impacts of diagram design by exploring the influence of visual context on non-cognitive outcomes.

\section{The Importance of Context}

Context is widely considered to be important in cognition and education. Since the latter half of the $20^{\text {th }}$ century, cognitive development theories tend to consider contextual factors to be inseparable from cognition and knowledge acquisition (Butterworth, 1992, p. 1; Ceci \& Roazzi, 1994, p. 74). In various branches of psychology context is not only considered as external factors relative to a given object, but also an internal quality that determines the conditions of knowledge activation and the limit of knowledge validity. It is often studied for, among other things, its influence on attention, and its priming effects on recall (Bazire \& Brézillon, 2005). Context has also been shown to influence cognitive strategies, outcome prediction, performance on Piaget's conservation tasks, and transfer of problem solving skills (Ceci \& Roazzi, 1994, pp. 77-83).

Context is particularly important for Constructivist approaches to education which are derived from a model of learning as an ongoing process of reconciling new information with existing mental models. In this framework new information always shares a conceptual overlap, or connection, with other information (Klassen, 2006), and therefore context becomes a critical influence on how new information is interpreted and understood. Klassen (2006) aptly describes learning as 'an attempt to find appropriate and desirable contexts into which to fit new knowledge', while Marton (1981) points out that even within the same individual, understanding of the same basic concept varies depending on the context in which it is applied.

Klassen (2006) notes that recent efforts in science education (scientific literacy, science for everyone, critical thinking, constructivism, contextual teaching) emphasize the importance of contextualising topics and teaching about science-how it was developed, how concepts relate to each other-rather than the facts of science alone. These efforts have been shown to have an impact on learning through elevated meaningfulness, relevance, knowledge transfer, motivation, and engagement (e.g. Bennett, Hogarth \& Lubben, 2003; Cordova \& Lepper,
1996; Gilbert, 2006).

Context is an extremely broad term. The general meaning of the word is too nebulous to be useful for research purposes, so a specific definition and demarcation of the scope of the term is required. In this study 'Context' refers to visual context in the form of a background illustration in a diagram. Illustrations used in this study were portrayals of locations that were germane to the informational content of the diagram. This included objects or entities within those locations that were either germane to the content, or germane to the location but extraneous to the content. In this study, consideration of context did not extend to other aspects such as the physical location or social setting of the viewing.

\section{Relevance and Its Roles in Attention, Motivation, and Learning}

Relevance is considered to play an important role in learning and motivation. Expectancy-Value theory considers 'value'-the degree to which a student values an activity-to be an important determinant of students' choices, performance, effort, and persistence with that activity (Wigfield \& Eccles, 2000). Here, 'value' is closely related to relevance, in that a sense of connection to individual experience, life goals, or personal values influences the attribution of value to a task, and the two constructs are often equated in the literature.

Motivational interest theories also point out the importance of relevance for its role in stimulating Triggered Situational Interest (interest in a particular situation or environment) and Maintained Situational Interest (a state of focussed attention), which in turn lead to longer term Individual Interest (Hidi \& Renninger, 2006). In their review paper Schraw and Lehman (2001) describe a number of studies which suggest relevance as a factor involved in determining interest, and since interest has positive influences on attention, recognition and recall, persistence and effort, academic motivation, learning, positive attitude, and cognitive performance (Hidi \& Renninger, 2006), relevance is a desirable characteristic for both formal and informal learning environments in a range of education and communication fields.

Unfortunately, relevance is not consistently defined across the literature, and in some cases is left undefined. Frymier and Shulman (1995) point out that in the educational psychology literature, relevance variously refers to the perception of how well course content satisfies personal needs, personal goals, or career goals, or a perceived connection between content and a student's goals, values, behaviours, ideas, or experiences. In this study relevance is defined as any perceived connection to the viewer (characteristics, ideas, interests, 
activities, customs, habits, experiences) or the viewer's goals (needs, desires, dreams, aspirations). This definition was adopted for its applicability for this study as well as for situating findings within existing frameworks involving relevance.

\section{Research Questions}

In a previous study (Wood \& Stocklmayer, 2018) we found qualitative evidence for a relationship between diagrammatic context and a perception of relevance. In that study, viewers of biological life cycle diagrams which included a contextual background illustration tended to perceive the information as personally relevant, more than viewers of similar diagrams without the contextual background. Viewers of the contextualised diagrams also felt more empathy and concern for the animals depicted.

Biological lifecycle diagrams are used in a range of situations, both in formal and informal learning environments, and are commonly depicted both with and without contextual backgrounds. A purely reductionist approach to the design of these diagrams is likely result in decontextualized designs, however given the importance of context and its relationship with relevance-another important construct for communication and learningit is worth investigating non-cognitive impacts of diagrammatic context that may be important for educational and communication outcomes.

In this study we employed quantitative methods across a larger sample of participants than our previous study, to address the following research questions.

How does the presence of visual context in a life cycle diagram affect viewers'...

- RQ1) ...perception of relevance of the information?

- RQ2) ...concern for the depicted animal?

- RQ3) ...perception of importance of the information presented?

- RQ4) ....interest in the information presented?

RQ1 and RQ2 were aimed at more broadscale confirmation of relationships uncovered in our earlier qualitative study (Wood \& Stocklmayer, 2018), while RQ3 and RQ4 targeted potential relationships identified from suggestions in the literature and from our own intuitions.

\section{METHODS}

\section{Experimental Design}

A $2 \times 2$ between groups comparison with Species (aquatic mussel/ gooseneck barnacle) and Context (context/ no context) as independent variables was conducted in the form of an online survey. Respondents were randomly assigned to one of four diagram conditions (mussel/ no context, mussel/ context, barnacle/ no context, barnacle/ context). After viewing their assigned diagram, respondents were then asked a series of comprehension questions, followed by attitude scale items measuring respondents' perceptions of relevance, interest, importance, and concern with respect to information represented in the diagram.

\section{Life Cycle Diagrams}

Context and No Context versions of generalized life cycle diagrams for an aquatic mussel and a gooseneck barnacle were developed specifically for use in this study (see Figure 1). Context and No Context versions were identical except for the presence or absence of a background scene. The No Context version simply showed the life stages arranged in a circle on a plain white background, in what might be termed the "traditional" presentation of a life cycle, while for the Context version this was overlaid on an illustration of the animal's habitat, with lines connecting each life stage with its location in the habitat. To preserve informational equivalency, brief text descriptions of each life stage, including location and habitat information, appeared in both versions.

\section{Comprehension Check}

A simple comprehension check was developed consisting of six multiple choice questions. The first was a self-assessment of understanding, this was followed by questions covering comprehension of key information presented in the diagram, and 'far transfer' application of comprehension to a question not addressed in the diagram. Rather than a comprehensive assessment of participants' understanding, this simple check was to confirm whether or not the inclusion of context had an obvious negative impact on comprehension. Comprehension questions are shown in Table 1.

\section{Development of Attitude Scales}

An attitude scale was developed targeting various aspects of relevance, along with situational interest, perceived importance of the information, and concern for the animal depicted in the diagram. Some scale items were adapted from related studies (e.g. Walker, 2012) but most were developed for this study. This process involved generating a 'raw' list of candidate scale items, then in consultation with colleagues, evaluating each item on its likelihood of accurately measuring the construct it targeted, and selecting items that were expected to be most effective. The resulting shorter list of items was then reviewed by independent volunteer subjects, and based on their feedback a final list was developed (Table 2). Each item was a five-point Likert scale (Strongly disagree, Disagree, Neutral, Agree, Strongly agree) asking 


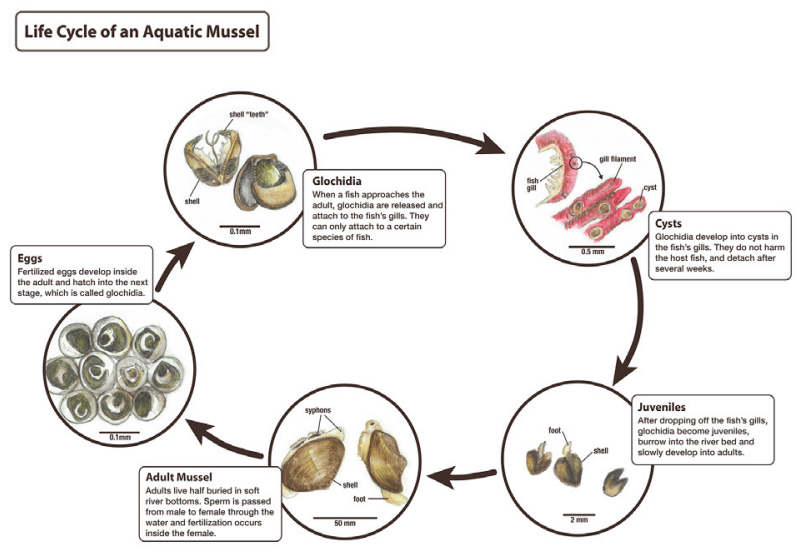

Mussel - No Context

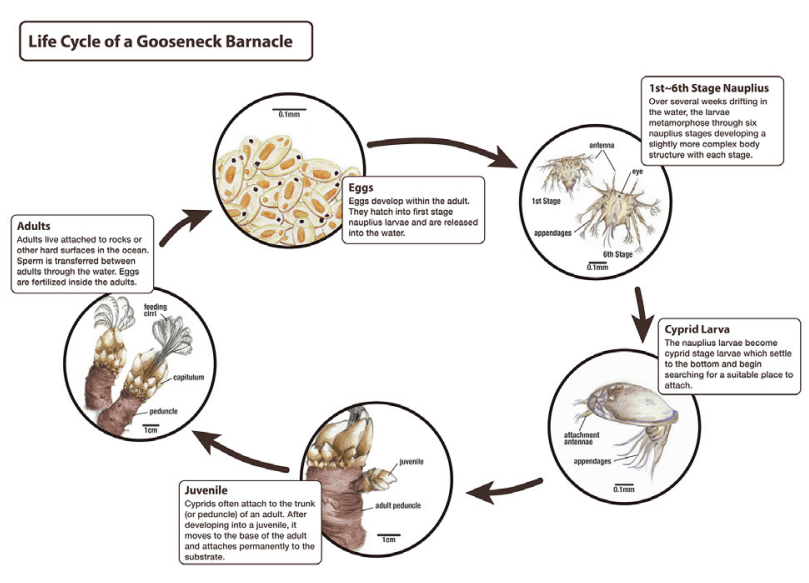

Barnacle - No Context

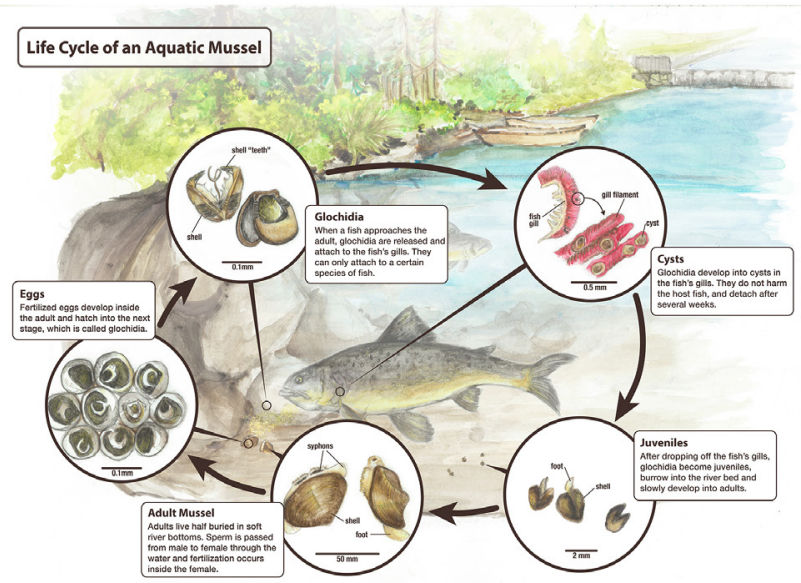

Mussel - Context

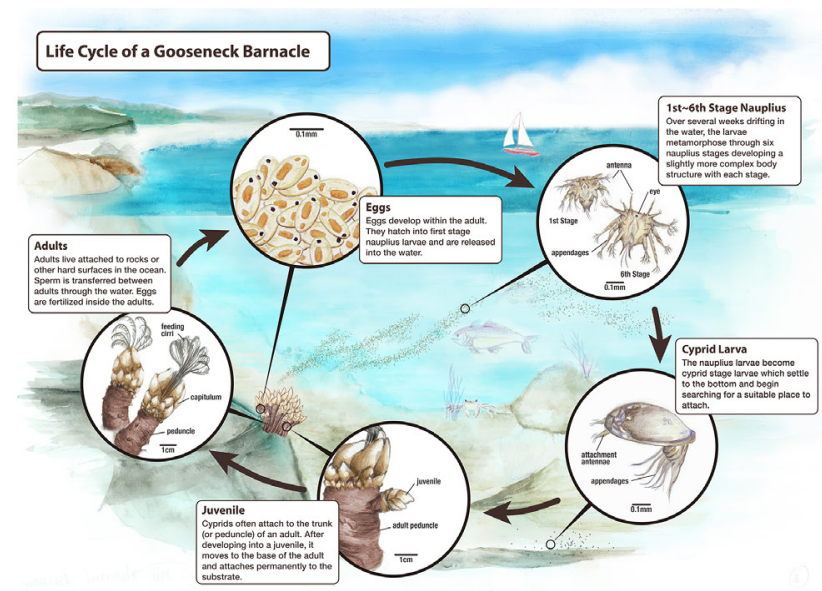

Barnacle - Context

Figure 1. Experimental diagrams. No Context and Context versions of generalised life cycle diagrams of an aquatic mussel and a gooseneck barnacle

participants' level of agreement or disagreement with a short statement. Responses were coded from 1 to 5 for statistical analysis.

\section{Administration of the Survey}

The study was administered using the commercially available survey platform surveygizmo.com to collect the data. Important priorities for the design of the survey were a reasonably short completion time to avoid participant fatigue, and clear, unambiguous questions and instructions that avoid influencing or biasing responses.

Upon commencing the survey, participants were given an explanation of the research project and asked for their consent to participate. They were then randomly allocated to one of the four diagram types and shown the corresponding diagram. Participants were instructed that they would subsequently be asked questions about the diagram, that they could view the diagram for as long as they wished, but would not be able to return to the diagram after proceeding. Next, participants were asked openended qualitative questions about their impressions of the diagram. This was followed by the comprehension check and then the attitudes scale. Participants were also asked additional qualitative questions, as well as questions on their attitudes toward nature, demographics, educational level, and prior experiences. The data for these questions are not discussed in this report, however they are mentioned here since they contributed to the overall length and structure of the survey, and consequently imposed restrictions on the length of the attitudes scale. Finally, participants were thanked for their time and provided with additional information on the study and how data would be used.

The majority of participants were recruited to the survey from an appeal post on the Facebook page of science media company ScienceAlert. At the time of this study the ScienceAlert Facebook page had 7 million subscribers, mostly in the USA, Australia, and India, 
Table 1. Questions used for comprehension check. Asterisks indicate correct answers

\section{All diagrams}

1) How well do you think you understood the life cycle you just saw?

- I didn't understand at all $\bullet$ I understood only a little • I understood quite well $\bullet$ I understood perfectly $\bullet$ I can't say Mussel diagrams

2) The life cycle you just saw was of what animal?

- Marine mussel • Aquatic mussel ${ }^{\star} \bullet$ Marine snail • Aquatic clam •I don't remember

3) Which of the following is the correct life cycle of the animal?

- Egg $>$ Glochidia $>$ Cyst $>$ Juvenile $>$ Adult* $\bullet$ Egg $>$ Cyst $>$ Glochidia $>$ Juvenile $>$ Adult $\bullet$ Egg $>$ Glochidia $>$ Juvenile $>$ Cyst $>$ Adult $\bullet$ Egg $>$ Cyst $>$ Juvenile $>$ Glochidia $>$ Adult $\bullet$ I don't know

4) Where does this animal live?

- River* • Lake • Ocean • Tidal pools •I don't know

5) Where are the animal's eggs fertilised?

$\bullet$ In the water $\bullet$ On the ground $\bullet$ Inside the adult* $\bullet$ Inside a fish $\bullet$ I don't know

6) Which of the following statements is most true?

- Fish are the natural enemy of this animal. • This animal causes a lot of damage to fish. • This animal can't survive without a fish.*

- Fish do not approach this animal. • I don't know

Barnacle diagrams

2) The life cycle you just saw was of what animal?

- Gooseneck Barnacle* • Gooseneck Clam • Barnacle Fan • Greyneck Barnacle •I don't remember

3) Which of the following is the correct life cycle of this animal?

- Egg > 1st 6th Stage Nauplius $>$ Cyprid $>$ Juvenile $>$ Adult* $\bullet$ Egg $>$ 1st 6 th Stage Nauplius $>$ Juvenile $>$ Cyprid $>$ Adult $\bullet$ Egg $>$ Cyprid $>$ 1st 6th Stage Nauplius $>$ Juvenile $>$ Adult $\bullet$ Egg $>$ Cyprid $>$ Juvenile $>$ 1st $\sim$ th Stage Nauplius $>$ Adult $\bullet$ I don't know

4) Where does this animal live?

- River • Lake • Ocean* • Sandy beach • I don't know

5) Where are the animal's eggs fertilised?

- In the water • On the ground • Inside the adult* • Attached to the adult • I don't know

6) Which of the following statements is most true?

- The animal relies on water currents to disperse long distances.* • The animal returns to the place it was born. • No other species can eat this animal. • Juveniles can distinguish their own parents. • I don't know

$41 \%$ of whom were female, and $78 \%$ under 35 years old (ScienceAlert Pty Ltd, n.d.). Remaining participants were recruited from two websites ${ }^{1}$ and a Reddit discussion group ${ }^{2}$ dedicated to recruiting volunteers for academic studies.

\section{Participants}

A total of 854 completed responses were collected, of which 24 were identified as speeders (less than 20 sec viewing diagram, or less than 5 min to complete the survey), straight-liners (all responses the same, or all but one response the same for attitude scale), or nonqualifiers (under 18 years) and subsequently removed, leaving $830^{3}$ clean responses for analysis. The sample comprised a younger age group (median age 31 years, though ranging from 18 to 88 years), with a small female majority (56.3\%). They represented 60 different countries, primarily Australia (31.7\%), the USA (30.8\%) and the UK (6.9\%). A high proportion of respondents were postsecondary educated (81.8\%), and many had tertiary level biology education (university biology courses $18.3 \%$, undergraduate major or postgraduate degree $26.9 \%$ ). Furthermore, $35 \%$ of respondents considered themselves to have a basic understanding of biology, while $60.2 \%$ rated their understanding as intermediate or expert level. The group was generally positive toward nature, with $86.9 \%$ interested or very interested in animals, nature and the environment, $61.2 \%$ spending time in nature at least once or more per month, and $96 \%$ reporting that they enjoy these experiences. This group was unlikely to 
Table 2. Attitudes scale targeting relevance, importance, interest and concern

\begin{tabular}{|c|c|c|}
\hline Item \# & Item wording & Target \\
\hline R1: & This animal and its life cycle are relevant to me. & User-defined relevance \\
\hline $\begin{array}{l}\text { R2: } \\
\text { R3: } \\
\text { R4: }\end{array}$ & $\begin{array}{l}\text { I can easily imagine this animal as part of the world I live in. } \\
\text { I feel connected with this animal and its environment. } \\
\text { I can see how this animal is linked to me and my own life. }\end{array}$ & Relevance: connection to self \\
\hline $\begin{array}{l}\text { R5: } \\
\text { R6: } \\
\text { R7: }\end{array}$ & $\begin{array}{l}\text { It's possible I could encounter this animal in real life. } \\
\text { I don't think I will ever see this animal in nature. } \\
\text { I have probably been to places where this animal lives. }\end{array}$ & Relevance: connection to experience \\
\hline $\begin{array}{l}\text { R8: } \\
\text { R9: }\end{array}$ & $\begin{array}{l}\text { This topic is connected to other things that I like. } \\
\text { I can't imagine how this animal connects with my interests. }\end{array}$ & Relevance: connection to interests \\
\hline $\begin{array}{l}\text { R10: } \\
\text { R11: }\end{array}$ & $\begin{array}{l}\text { I can use this information in practical situations. } \\
\text { Knowing about this life cycle might help me with other things that I do. }\end{array}$ & $\begin{array}{l}\text { Relevance: connection to the viewer's } \\
\text { goals (Utility) }\end{array}$ \\
\hline $\begin{array}{l}\text { IMP1: } \\
\text { IMP2: }\end{array}$ & $\begin{array}{l}\text { It's important for me to know about this animal. } \\
\text { The more people that know about this animal the better. }\end{array}$ & Importance \\
\hline $\begin{array}{l}\text { TSI1: } \\
\text { TSI2: }\end{array}$ & $\begin{array}{l}\text { I enjoyed looking at this diagram. } \\
\text { Understanding this life cycle felt like hard work. }\end{array}$ & Triggered Situational Interest \\
\hline $\begin{array}{l}\text { MSI1: } \\
\text { MSI2: }\end{array}$ & $\begin{array}{l}\text { I want to know more about this animal and how it lives. } \\
\text { I have no interest in this animal at all. }\end{array}$ & Maintained Situational Interest \\
\hline $\begin{array}{l}\text { CON1: } \\
\text { CON2: }\end{array}$ & $\begin{array}{l}\text { I'm concerned about what happens to this animal. } \\
\text { I would feel bad if this animal were to disappear. }\end{array}$ & Concern \\
\hline
\end{tabular}

* Reverse coded item

be representative of the wider population and this was probably a function of the recruitment method (interested volunteers who were recruited mostly from a young group of subscribers to a science news service). Representative sampling was not logistically possible for this study, but while it is something to consider when interpreting the findings, a non-representative sample does not nullify the results of the study.

\section{Statistical Analysis}

Data was analysed using the statistical computing and graphics language R (Version 3.3.1) (R Core Team, 2016) and development environment R Studio (Version 0.99.903) (RStudio Team, 2015). Add-on packages 'dplyr' (Wickham \& Francois, 2016), 'psych' (Revelle, 2016), 'GPArotation' (Bernaards \& Jennrich, 2005), 'moments' (Komsta \& Novomestky, 2015), and 'MASS' (Venables \& Ripley, 2002) were used for specific statistical functions, and 'ggplot2' (Wickham, 2009) for data plots and output.

\section{RESULTS AND ANALYSIS Comprehension Check}

A simple unweighted comprehension score was calculated for each participant by awarding one point for each correct answer for comprehension questions 2 6. The mean performance of participants in the No Context and Context conditions for each species were then compared using a Student's t-test. No significant difference was detected between No Context and Context scores for the mussel group (No Context mean $=3.64$; Context mean $=3.82 ; \mathrm{t}(429.46)=1.71 ; \mathrm{p}=.088)$. However for the barnacle group, participants showed improved scores in the Context condition (No Context mean $=3.68$; Context mean $=3.93 ; t(386.71)=2.27 ; p=.024$; Cohen's $d$ $=0.23$ ).

A chi-squared test for independence was used to examine the distributions of answers for individual questions. All incorrect answers were pooled and the binary distributions of correct/ incorrect responses were compared between No Context and Context conditions for both the Barnacle and Mussel groups. Only one of the comprehension questions showed a statistically significant difference in the distribution of correct and incorrect answers between No Context and Context groups, and that was the habitat question ("Where does this animal live?"). Both Barnacle and Mussel groups showed an increase in correct answers to this question under the Context condition (Table 3).

\section{Attitude Scale Validity}

The attitude scale used in this study was newly developed, so it was important to determine that scale items behaved as expected, and that they did indeed measure the constructs they were intended to target. 
Table 3. Chi-squared test of independence on correct and incorrect responses to habitat question for No Context and Context conditions in Barnacle and Mussel groups

\begin{tabular}{|c|c|c|c|c|}
\hline & \multicolumn{2}{|l|}{ Barnacle } & \multicolumn{2}{|l|}{ Mussel } \\
\hline & No Context & Context & No Context & Context \\
\hline Correct responses & 138 & 163 & 101 & 127 \\
\hline \multirow[t]{2}{*}{ Incorrect responses } & 60 & 30 & 122 & 80 \\
\hline & \multicolumn{2}{|c|}{$X^{2}=11.20, d f=1, p<.001$} & \multicolumn{2}{|c|}{$X^{2}=10.49, d f=1, p=.001$} \\
\hline
\end{tabular}

Exploratory factor analysis (EFA) was conducted to determine whether grouped scale items correlated with each other-an indication that they were accurately targeting the intended underlying constructs. The EFA was conducted using R (Version 3.3.1) (R Core Team, 2016) and R Studio (Version 0.99.903) (RStudio Team, 2015), and following the procedure outlined by Buchanan (2016).

Missing data and outliers were removed leaving 804 responses with interval data for 19 variables, satisfying FA requirements of 300 or more samples of at least interval data with 5 or more variables. The data also showed acceptable mean sampling adequacy Kaiser-MeyerOlkin test: $M S A=.93)$, scale item correlation adequacy (Bartlet's test: $X^{2}(171)=6507.83, p<.001$ ), and no signs of multicollinearity or excessively correlated variables (max correlation $\mathrm{R}=.64$ ). Analysis of distribution plots, skewness, and Kurtosis scores showed that most items fell into acceptable ranges of normality, however it should be noted that normally distributed data, while preferred, is not a strict requirement for factor analysis (Coakes, Steed, \& Ong, 2010, p. 134), particularly when it is used to summarize relationships between large numbers of variables (Tabachnick \& Fidell, 2007, p. 613) as it was in this study. Transformation of the data did not improve normality so analysis was conducted on non-transformed data.

Parallel analysis, scree plot examination, and Kaiser criteria were used to determine the number of factors to be used for EFA. Parallel analysis suggested 6 factors, the scree plot suggested 2 , and Kaiser criteria suggested 1 (eigenvalues $>1$ ) or 2 (eigenvalues > .7). This gave a broad range of suggestions from 1 to 6 . EFA is often focused on maximum data reduction, or explaining as much as possible of the variance among a large number of variables using the smallest possible number of underlying factors. In this study however, the focus was on the relationships between items and underlying constructs rather than maximum reduction of complexity. With this in mind EFA was trialled with two-, three-, and four-factors.
The four-factor solution was deemed to be the best compromise between data compression and excessive removal of items that didn't fit the simpler solutions, thus providing a framework to understand the relationships between items, while maintaining enough resolution to be useful for our purposes.

Two items needed to be removed from the four-factor solution-R2 for failing to load sufficiently on any factor, and MSI1 for co-loading on multiple factors. The resulting model had very good fit indices (RMSR $=.03$, Tucker Lewis $=.935, \mathrm{RMSEA}=.058, \mathrm{CFI}=.965)$, acceptable reliability scores (raw alpha Factor $1=.87$, Factor $2=.78$, Factor 3 $=.77$, Factor $4=.74$ ) and explained $51 \%$ of the variance. Factor loadings of individual items are given in Table 4, and correlations between factors can be seen in Figure 2 .

Apart from the two non-performing items, R2 and MSI1, items targeting the same underlying construct loaded together, confirming that the attitude scale items correlated with each other as expected, and suggesting that they were valid indicators of the constructs they were targeting. Items for Triggered Situational Interest and Maintained Situational Interest loaded together onto the same factor, suggesting the attitude scale could not distinguish between these two closely related constructs at a four-factor level of analysis. Rather, the items grouped together as the broader construct of Situational Interest. For subsequent analysis, items were grouped into composite variables representing the underlying constructs they targeted (Table 4).

\section{Relationships between Constructs}

The loading of Relevance as a Connection to Self (Rself) items with Importance (Imp) and Concern (Con) items on factor ML1 (Importance, Concern, Connection to Self) suggests a close relationship between these constructs. Similarly, Relevance as a Connection to Interests (Rint) items loaded with Situational Interest (Int) items on factor ML3 (Interest) as might be expected given their common concern with participant interest. Factor correlations (Figure 2) also showed that ML1 (Rself, Imp, Con) correlated 


\section{Importance/ Concern/ Connection to self}

Interest

Experience

Utility

\begin{tabular}{|c|c|c|c|c|c|c|c|}
\hline \multicolumn{2}{|r|}{ Item number and wording } & \multirow{2}{*}{$\begin{array}{c}\text { ML1 } \\
.50\end{array}$} & \multirow[t]{2}{*}{ ML3 } & \multirow[t]{2}{*}{ ML2 } & \multirow[t]{2}{*}{ ML4 } & \multirow{2}{*}{$\begin{array}{c}\text { h2 } \\
.61\end{array}$} & \multirow{3}{*}{$\begin{array}{l}\text { Construct variable } \\
\text { Rself: } \\
\text { Relevance as connection to self }\end{array}$} \\
\hline $\mathrm{R} 1$ & This animal and its life cycle are relevant to me. & & & & & & \\
\hline R3 & I feel connected with this animal and its environment. & .55 & & & & .51 & \\
\hline R4 & $\begin{array}{l}\text { I can see how this animal is linked to me and my own } \\
\text { life. }\end{array}$ & .44 & & & & .43 & \\
\hline R5 & It's possible I could encounter this animal in real life. & & & .79 & & .63 & \\
\hline R6 & I don't think I will ever see this animal in nature. & & & .78 & & .62 & $\begin{array}{l}\text { Rexp: } \\
\text { Relevance as connection to }\end{array}$ \\
\hline $\mathrm{R} 7$ & I have probably been to places where this animal lives. & & & .66 & & .43 & \\
\hline $\mathrm{R} 8$ & This topic is connected to other things that I like. & & .73 & & & .55 & Rint: \\
\hline R9 & $\begin{array}{l}\text { I can't imagine how this animal connects with my } \\
\text { interests. }\end{array}$ & & .69 & & & .56 & $\begin{array}{l}\text { Relevance as a connection with } \\
\text { interests }\end{array}$ \\
\hline $\mathrm{R} 10$ & I can use this information in practical situations. & & & & .64 & .60 & \\
\hline R11 & $\begin{array}{l}\text { Knowing about this life cycle might help me with other } \\
\text { things that I do }\end{array}$ & & & & .59 & .56 & Relevance as utility \\
\hline IMP1 & It's important for me to know about this animal & .57 & & & & .58 & Imp: \\
\hline IMP2 & $\begin{array}{l}\text { The more people that know about this animal the } \\
\text { better. }\end{array}$ & .67 & & & & .48 & Perceived importance of the topic \\
\hline TSI1 & I enjoyed looking at this diagram. & & .45 & & & .32 & \\
\hline $\mathrm{TS} 12$ & Understanding this life cycle felt like hard work. & & .43 & & & .16 & $\begin{array}{l}\text { Int: } \\
\text { Situational Interest }\end{array}$ \\
\hline MSI2 & I have no interest in this animal at all. & & .62 & & & .59 & \\
\hline CON1 & I'm concerned about what happens to this animal. & .80 & & & & .59 & Con: \\
\hline CON2 & I would feel bad if this animal were to disappear. & .51 & & & & .36 & $\begin{array}{l}\text { Concern for the animal in the } \\
\text { diagram }\end{array}$ \\
\hline Eigen & values of original matrix & 6.84 & 1.63 & 1.14 & 0.96 & & \\
\hline Prope & ortion of total variance & 0.18 & 0.14 & 0.11 & 0.08 & & \\
\hline Cumb & ulative variance & 0.18 & 0.32 & 0.43 & 0.51 & & \\
\hline
\end{tabular}

strongly (.7) with ML3 (Rint, Int), moderately (.5) with ML4 (containing Relevance as utility (Ruti)), and moderately (.4) with ML2 (containing Relevance as experience (Rexp)). ML3 showed moderate correlations with ML4 (.5), and ML2 (.4). It is interesting that while relationships between Relevance and other constructs of Interest, Importance, and Concern are discussed in the literature and may be have been a predictable outcome here, it is clear from these results that such relationships are dependent on the aspect of relevance under scrutiny.

\section{Impact of Context on Relevance and Concern}

To investigate the impact of diagram context on each of the constructs measured by the attitude scale, species data (gooseneck barnacle, aquatic mussel) were separated and t-tests were conducted to compare mean 


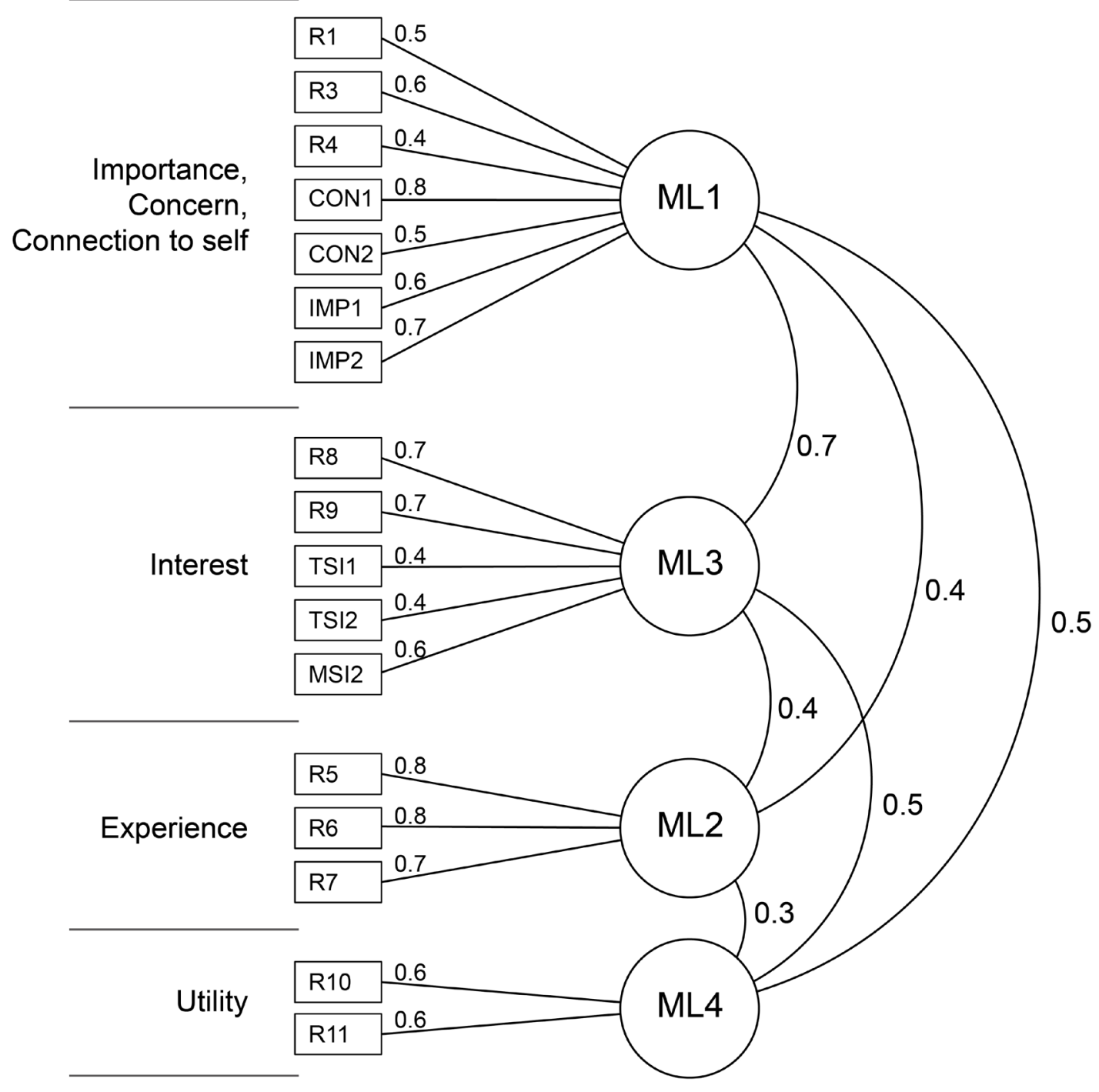

Figure 2. Factor diagram for four-factor EFA solution showing item loadings and factor correlations

scores for each of the construct variables between No Context and Context groups. The mussel data showed no statistically significant difference on any of the construct variables. However, for the barnacle group, there were statistically significant increases from No Context to Context conditions in $\operatorname{Rexp}(\mathrm{t}(379.91)=2.96, \mathrm{p}=.003)$ and Con $(\mathrm{t}(380.89)=2.19, \mathrm{p}=.03)$ (see Table 5).

This suggests that the inclusion of visual context in a diagram had a small but significant effect on viewers' perception of a connection between the gooseneck barnacle information and their own personal experience, along with an impact on their sense of concern for the animal. Even a small effect size is worth noting given the large sample size (383 datapoints for barnacle group).

However, if adjustments are made to avoid the possibility of inflated Type I error rate due to multiple testing, the change in Rexp remains significant, but confidence in the validity of the effect on Con diminishes. (Benjamini-Hochberg correction Rexp: $p=0.02$, Con: $p=$
0.10). This leaves some uncertainty over whether or not the effect of context on concern is a true result.

A comparison of the change in mean Rexp scores with context between the mussel and barnacle groups reveals an interesting difference. Mean Rexp score rose from No Context to Context conditions in the barnacle group, but for the mussel group mean Rexp remained flat across conditions at a level similar to the Context condition of the barnacle group. In other words, Context was associated with higher Rexp scores than No Context for barnacle data, whereas in the mussel group, scores were consistently higher regardless of context (Figure 3).

\section{DISCUSSION \\ Research Questions}

The results reported here provide clear evidence that there was in fact a relationship between the presence of visual context in diagrams and viewers' perceptions of the relevance of that information (RQ1). Specifically, viewers' 
Table 5. Comparison of mean Rexp and Con scores for No Context and Context treatments in the barnacle group

\begin{tabular}{|c|c|c|c|c|}
\hline & \multicolumn{2}{|c|}{$\operatorname{Rexp}^{*}$} & \multicolumn{2}{|c|}{ Con $^{\dagger}$} \\
\hline & mean & sd & mean & sd \\
\hline No context & 9.92 & 2.58 & 6.96 & 1.65 \\
\hline \multirow[t]{3}{*}{ Context } & 10.71 & 2.63 & 7.32 & 1.62 \\
\hline & \multicolumn{2}{|c|}{$t(379.91)=2.96, p=0.003$} & \multicolumn{2}{|c|}{$t(380.89)=2.19, p=0.03$} \\
\hline & \multicolumn{2}{|c|}{ Cohen's d = 0.30 (small) } & \multicolumn{2}{|c|}{ Cohen's d = 0.22 (small) } \\
\hline
\end{tabular}

were more likely to feel that the information in a diagram was more connected to their own everyday experience when the diagram contained a contextual background. Interestingly, this relationship was evident for only one of the species used in this study-the gooseneck barnacle. For the mussel species, perceived relevance under the no-context condition was higher than that of the barnacle group, and did not change with the addition of context. This suggests that the effect of context observed here may have been a compensatory effect, helping to stimulate a sense of relevance for a topic that was not inherently considered relevant. For a topic that was already perceived as relevant, the addition of context did not increase that further. It is to be expected that the response to visual context is likely to vary according to the specific characteristics of the individual viewer, but these results suggest that subject matter along with an individual's relationship with that subject matter, is also likely to influence any impacts of visual context.

This study also uncovered evidence for a relationship between visual context and an elevated sense of concern (RQ2). Although the statistical significance of this relationship was reduced by conservative adjustments aimed at avoiding Type I errors under multiple testing situations, we feel that this relationship should not be completely discounted, particularly since we saw clear qualitative evidence for such a relationship in an earlier study (Wood \& Stocklmayer, 2018). Given the indications of a context - concern relationship in two separate studies, and also considering the implications such a relationship mighthave for practitioners in areassuch asenvironmental communication or health communications, we feel that this deserves further scrutiny to clarify its extent and validity.

There were no indications of visual context having a direct relationship with perceived importance (RQ3), or with elevated interest (RQ4). The correlations between factors in the EFA showed moderate connections between Relevance as a connection to experience (which did vary significantly with context) and factors representing Importance and Interest, which suggests there may be some secondary correlation of importance and interest with context, via relevance. However any impact of context on importance or interest was too small to be detected in this study.

\section{The Relationship between Context, Relevance, and Interest}

A relationship between context and relevance is likely to be important given that the literature suggests a series of links between relevance and situational interest (Hidi \& Renninger, 2006; Schraw \& Lehman, 2001), between situational interest and individual interest (Hidi \& Renninger, 2006), and between individual interest and improvements in attention, recognition, recall, persistence, effort, academic motivation, learning, positive attitude, and cognitive performance (Hidi \& Renninger, 2006). The literature also reports direct connections of relevance with motivation (Frymier \& Shulman, 1995), interest, and class performance (Hulleman, Godes, Hendricks, \& Harackiewicz, 2010; Hulleman \& Harackiewicz, 2009).

In this project, we found context to have an influence on Relevance (as experience), however there was no clear indication of a subsequent impact on Situational Interest, as might be expected from other reports in the literature. One possible reason for this lies with how relevance is defined. 'Relevance' in the literature variously refers to usefulness, importance, connection to interests and experience, or is left undefined. Perhaps the experience aspect of relevance in this project was qualitatively different from the relevance examined in other studies in the literature, resulting in different relationships between context and downstream motivation constructs. Alternatively, the apparent lack of impact of context on 


\section{Change in mean Rexp scores with Context by Species}

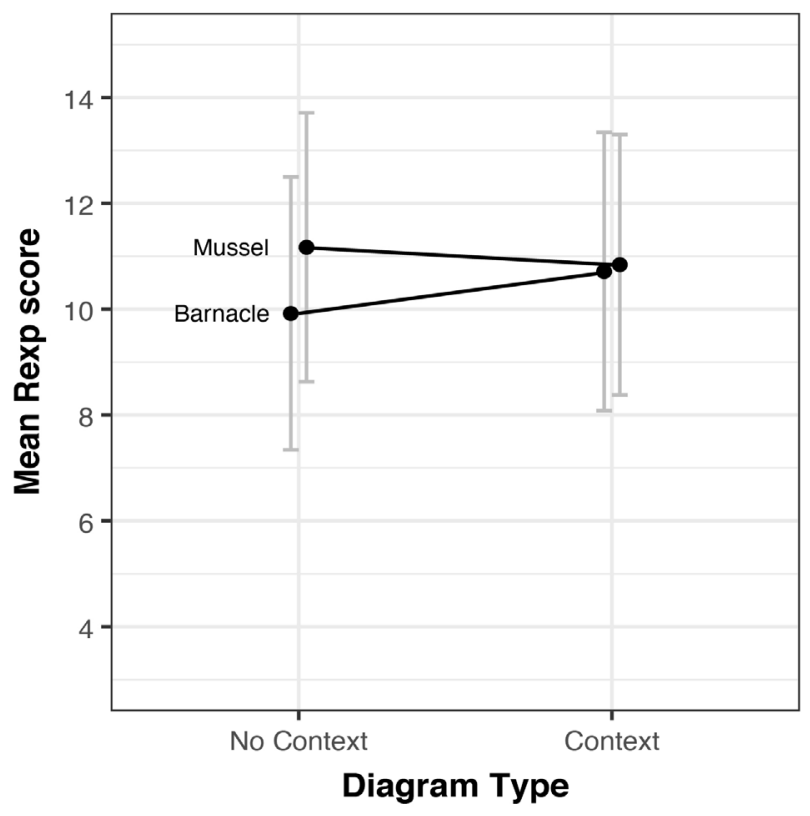

\begin{tabular}{rcc}
\hline Mussel & $11.17 \pm 2.54$ & $10.84 \pm 2.46$ \\
Barnacle & $9.92 \pm 2.58$ & $10.71 \pm 2.63$ \\
\hline
\end{tabular}

Figure 3. Difference in mean Rexp scores between context treatments for each species group. Error bars show standard deviations

Situational Interest may have been because any influence was simply too small to detect across the diverse range of participants in this study.

However, these findings do suggest the potential for a positive impact of context on SI (and the subsequent benefits which that entails). Context was clearly associated with feelings of relevance in this project, and the literature asserts that relevance leads to interest. In the specific setting of this research, it was an aspect of relevance related to personal experience that was most affected by context, but it is reasonable to expect that other aspects of relevance may also be influenced by different types of context or under different conditions. If the context - relevance relationship is further elucidated in conjunction with identification of specific aspects of relevance that are most likely to lead to elevated interest, it may be possible to target interest through specific context designs. The implications this could have for a range of communication and education settings are self-evident.

\section{Defining Specific Aspects of Relevance}

This study also revealed some unexpected insights into the nature of the relevance construct. As we have mentioned, relevance is not consistently or rigorously defined in the literature. Its general meaning is very broad, but for research purposes it is usually taken as narrower, more specific constructs which differ between research projects according to particular aims and needs. For this project, relevance was defined as 'a perceived connection to the viewer (values, characteristics, ideas, interests, activities, customs, habits, experiences) or the viewer's goals (needs, desires, dreams, aspirations)', and items targeting various aspects of this definition (self, experience, interests, and utility) were developed for use in the attitude scale. EFA revealed that although these aspects of relevance were related to each other, they were in some cases more closely related to other constructs altogether. Relevance (self) was very closely related to Importance and Concern, and Relevance (interest) was related to Situation Interest, while Relevance (experience) and Relevance (utility) appeared to be more distinct from the other aspects. It seems that rather than being a single construct, relevance, as it was defined in this study, is a conglomerate of narrower constructs, which may have more in common with other constructs considered to be separate from relevance than they do with each other. The literature certainly suggests such relationships, for example between relevance and interest, but our results highlight the importance of specificity when targeting 
relevance, and have important implications for relevance studies.

\section{The Potential of Context as an Aid to Comprehension}

The comprehension check in this study was intended to be a simple confirmation of whether the addition of context was an obvious detriment to understanding. There was no evidence of such a negative impact. In fact there were small improvements in participants' recall of the habitat of the subject animal, an aspect of the content related to the context. This information was included in the text descriptions for both No Context and Context diagrams, but the visual depiction of the habitat in the Context diagrams seemed to reinforce this information. This confirms that design choices that might sometimes be considered superfluous visual embellishment or decorations can actually play a role in consolidating target information in cases where there is a direct depiction of some aspect of the target information, as there was in this example. However, more importantly for the objectives of this study, these results show that the inclusion of context in the diagrams used in this study did not impose additional cognitive load that might jeopardize the educational objectives of the diagrams. Cognitive Load Theory predicts that when cognitive resources are in high demand, for example when processing more challenging content, the additional cognitive load due to visual distractions could result in diminished comprehension and recall. Although that did not appear to be the case for the diagrams in this study, outcomes might be different for diagrams presenting more cognitively challenging material.

\section{FINAL COMMENTS}

This study demonstrated that the presence of visual context in a diagram can influence perceptions of the relevance of the information presented, and the moderate effect sizes detected in this study have the potential to be far more important when considering impacts over multitudinous viewings during an individual's lifetime, or across an entire population.

Since relevance has been linked to higher interest, motivation, and learning performance, these findings have important implications for a range of education and communication fields where diagrams or graphics are employed in either formal or informal learning settings. Thisincludes, but is not limited to, science education, along with science, environmental, and health communications. of course the context - relevance relationship is unlikely to be a simple one. It is likely to depend on characteristics of the context, the subject matter, and the viewer, as well as specific aspects of the relevance construct. Further clarification of these complexities could offer a valuable addition to the toolset of educators, communicators, and diagram designers.

More broadly, this study shows that in addition to important cognitive impacts, diagram design choices can also have influences on affective and emotional responses that might make important contributions toward education and communication objectives.

\section{NOTES}

${ }^{1}$ Online Psychology Research (www. onlinepsychologyresearch.com); Call for Participants (www. callforparticipants.com)

${ }^{2}$ SampleSize (https://www.reddit.com/r/SampleSize/)

${ }^{3}$ In addition, a small number of responses with missing data, outliers, or otherwise unusable data were excluded from some statistical analyses. The maximum number of usable data points was used for each analysis, but this varied from test to test depending on the specific requirements and conditions of the test. Subsequently N values vary to a small degree between analyses.

\section{ACKNOWLEDGEMENTS}

We would like to express our sincere gratitude to the many participants who volunteered their time to contribute to this study. This research did not receive any specific funding from public, commercial, or not-for-profit sources.

\section{REFERENCES}

Bazire, M., \& Brézillon, P. (2005). Understanding context before using it. Modeling and using context, 3554, 29-40. doi:10.1007/11508373_3

Bennett, J., Hogarth, S., \& Lubben, F. (2003). A systematic review of the effects of context-based and science-technologysociety (sts) approaches in the teaching of secondary science. EPPI-Centre, Social Science Research Unit, Institute of Education, University of London.

Bernaards, C. A., \& Jennrich, R. I. (2005). Gradient projection algorithms and software for arbitrary rotation criteria in factor analysis. Educational and Psychological Measurement, 65, 676-696. Retrieved from http://www.stat.ucla.edu/ research/gpa

Buchanan, E. (2016). $R$ - exploratory factor analysis lecture \& example. Retrieved from https://youtu.be/uPFQQtdKCAM

Butterworth, G. (1992). Context and cognition in models of cognitive growth. In Context and cognition: Ways of learning and knowing (pp. 1-13). Hertfordshire: Harvester Wheatsheaf.

Ceci, S. J., \& Roazzi, A. (1994). The effect of context on cognition: postcards from brazil. In R. J. Sternberg \& R. K. Wagner (Eds.), Mind in context: Interactionist perspectives on human intelligence (pp. 74-104). Cambridge: Cambridge University Press.

Coakes, S. J., Steed, L., \& Ong, C. (2010). SPSS: analysis without anguish: version 17.0 for windows. Milton: John Wiley \& Sons. 
Cook, M. P. (2006). Visual representations in science education: the influence of prior knowledge and cognitive load theory on instructional design principles. Science Education, 90(6), 1073-1091. doi:10.1002/sce.20164

Cordova, D. I., \& Lepper, M. R. (1996). Intrinsic motivation and the process of learning: beneficial effects of contextualization, personalization, and choice. Journal of Educational Psychology, 88(4), 715-730. doi:10.1037/0022-0663.88.4.715

Frymier, A. B., \& Shulman, G. M. (1995). "What's in it for me?": increasing content relevance to enhance students' motivation. Communication Education, 44(1), 40-50. doi:10.1080/03634529509378996

Gilbert, J. K. (2006). On the nature of "context" in chemical education. International Journal of Science Education, 28(9), 957-976. doi:10.1080/09500690600702470

Hegarty, M., Smallman, H. S., \& Stull, A. T. (2012). Choosing and using geospatial displays: effects of design on performance and metacognition. Journal of Experimental Psychology: Applied, 18(1), 1-17. doi:10.1037/a0026625

Heidig, S., Müller, J., \& Reichelt, M. (2015). Emotional design in multimedia learning: differentiation on relevant design features and their effects on emotions and learning. Computers in Human Behavior, 44, 81-95. doi:10.1016/j. chb.2014.11.009

Hidi, S., \& Renninger, K. A. (2006). The four-phase model of interest development. Educational Psychologist, 41(2), 111127. doi:10.1207/s15326985ep4102_4

Hulleman, C. S., Godes, O., Hendricks, B. L., \& Harackiewicz, J. M. (2010). Enhancing interest and performance with a utility value intervention. Journal of Educational Psychology, 102(4), 880-895. doi:10.1037/a0019506

Hulleman, C. S., \& Harackiewicz, J. M. (2009). Promoting interest and performance in high school science classes. Science (New York, N.Y.), 326(5958), 1410-2. doi:10.1126/ science. 1177067

Klassen, S. (2006). A theoretical framework for contextual science teaching. Interchange, 37(1-2), 31-62. doi:10.1007/ s10780-006-8399-8

Komsta, L., \& Novomestky, F. (2015). Moments: moments, cumulants, skewness, kurtosis and related tests. Retrieved from https://cran.r-project.org/package=moments

Marton, F. (1981). Phenomenography - describing conceptions of the world around us. Instructional Science, 10, 177-200. doi:10.1007/BF00132516

Mayer, R. E., \& Moreno, R. (2002). Animation as an aid to multimedia learning. Educational Psychology Review, 14(1), 87-100. doi:10.1023/A:1013184611077

Park, B., Flowerday, T., \& Brünken, R. (2015). Cognitive and affective effects of seductive details in multimedia learning. Computers in Human Behavior, 44, 267-278. doi:10.1016/j. chb.2014.10.061

Park, B., Moreno, R., Seufert, T., \& Brünken, R. (2011). Does cognitive load moderate the seductive details effect? A multimedia study. Computers in Human Behavior, 27, 5-10. doi:10.1016/j.chb.2010.05.006

Plass, J. L., Heidig, S., Hayward, E. O., Homer, B. D., \&Um, E. (2014). Emotional design in multimedia learning: effects of shape and color on affect and learning. Learning and Instruction, 29, 128-140. doi:10.1016/j.learninstruc.2013.02.006

R Core Team. (2016). R: a language and environment for statistical computing. Vienna, Austria: R Foundation for Statistical Computing. Retrieved from https://www.rproject.org/

Revelle, W. (2016). Psych: procedures for personality and psychological research. Evanston, Illinois, USA: Northwestern University. Retrieved from https://cran.rproject.org/package=psych

RStudio Team. (2015). RStudio: integrated development for r. Boston, MA: RStudio Inc. Retrieved from http://www. rstudio.com/

Schneider, S., Nebel, S., \& Rey, D. (2016). Decorative pictures and emotional design in multimedia learning. Learning and Instruction, 44,65-73. doi:10.1016/j.learninstruc.2016.03.002

Schraw, G., \& Lehman, S. (2001). Situational interest: A review of the literature and directions for future research. Educational Psychology Review, 13(1), 23-53. doi:10.1023/A:1009004801455

ScienceAlert Pty Ltd. (n.d.). ScienceAlert media kit. Retrieved from www.sciencealert.com

Smallman, H. S., \& St John, M. (2005). Naive realism: limits of realism as a display principle. Proceedings of the Human Factors and Ergonomics Society 49th Annual Meeting. doi:10.1177/154193120504901714

Tabachnick, B. G., \& Fidell, L. S. (2007). Using multivariate statistics (5th Ed.). Boston: Pearson Education.

Trumbo, J. (2000). Essay: seeing science: research opportunities in the visual communication of science. Science Communication, 21(4), 379-391. doi:10.1177/1075547000021004004

Venables, W. N., \& Ripley, B. D. (2002). Modern applied statistics with s. New York: Springer.

Walker, G. J. (2012). Motivational features of science show. Australian National University.

Wickham, H. (2009). Ggplot2: elegant graphics for data analysis. New York: Springer-Verlag.

Wickham, H., \& Francois, R. (2016). Dplyr: a grammar of data manipulation. Retrieved from https://cran.r-project.org/ package $=$ dplyr

Wigfield, A., \& Eccles, J. S. (2000). Expectancy-value theory of achievement motivation. Contemporary Educational Psychology, 25(1), 68-81. doi:10.1006/ceps.1999.1015

Wiley, J. (2019). Picture this! effects of photographs, diagrams, animations, and sketching on learning and beliefs about learning from a geoscience text. Applied Cognitive Psychology, 33(1), 9-19. doi:10.1002/acp.3495

Wood, M., \& Stocklmayer S. M. (2018). Exploring the relationship between visual context and affect in diagram interpretation. In P. Chapman, G. Stapleton, A. Moktefi, S. Perez-Kriz, \& F. Bellucci (Eds.), Diagrammatic Representation and Inference. Diagrams 2018. Lecture Notes in Computer Science, vol 10871. Springer, Cham. doi:10.1007/978-3-319-91376-6_46 